DEPARTAMENTO DE. CLÍNICA MÉDICAS I DIRETOR: Prof. Dr. Sobostizo N. Pirotininga

DFPARTAMENTO DE MICROBIOLOGIA E IMUNOLOGIA DIRETOR: Prof. Dr. Poulo M. G. de Locerdo Junior

\title{
ESPOROTRICOSE EM CÃES
}

(Sporotricosis in dogs)

M. F. Migliono
Professor Associodo
D. C. de Freitos

Professor Assistente
G. Moreno

Instrutor

A esporulricose é micose pouco freqliente em animais domés ticos, cmbora terha sido ajuinalada um várias espécies (Vanbrawegham, 1958). Após o trabalho de LiTZ e SPLENDORE (1907), sôbre a 으 corrência do agente etiológlco em ratos, poucä referências foram a dicionada: à litcratura brasileira e tôdas clas caracterlzada; por observações de casos isolados.

Pudcmo:s reunir até o presente, as publicações de AREA IER̃o e col. (1935) e PIRATININGA (1943) concementes à ocorrência da moléstia em muares, a rotificação de um caso em jumento, feita por Mifo (1935), a verificação de um caso em gato, referida pas FRETTAS e col. (1956) e a comuntcação de SOUZA (I957) en cão. Nossa ubservação de 2 casos de esporotricose em cão vem somar-se a essa literatura, Justificando a apresentação dêste trabạ Iho, una vez que não há referênclas a tal hospedeiro, S. Paulo. Em rolação ao homem, a frequêncla desta micose é relativa mente balxa. Segundo LACAZ (1960) a esporotricose fol verifica da apenas em $0,5 \%$ de 20.470 pacientes matriculados no Ambulató. rio de Dematolegia de Hosfital das Clínicas, durante os anos 
de 1945 a 1953.

DESCRIÇR̃O DOS CASOS

CASO 1. Em 23.5.61 examinamos un cão Boxer, com 2 anos de idade, macho, nascido no Estado da Guanabara $c$ que velo para São Paulo com 3 meses de idade. Nessa ocarião reve lou o proprletário - o animal já apresentava sintomas de distrufia óssea responsável pelos defeltos de aprumo que observamos e que po dem ser ident1ficados na Foto 1 .

Cêrca de dois meses antes, o proprietário notou o apareci mento de lesões na pele, inicialmente localizadas na ponta das ore Thas, atribufdas a môscas hematófagas e caracterizadas por formaçã de crostas que, removidas, provocavam hemorragia. Ais lesõe. alas traram-se insidiosamente e passaram a surgir em todo o corro, atin glndo simultâneamente foclnho, região toráclca, perianal e nível das articulaçõcs do cotovêlo e joelho.

O processo vinha sendo tratado com pomada contendo sulfa mida, óxido de zinco e óleo de fígado de bacalhau, sem resultado.

o exame geral do animal revelou bom estado de nutrição (a pesar das sequelas da distrofla óssea), temperatura nos limites da normalidade $\left(38,8^{\circ} \mathrm{C}\right)$, pulso regular com 100 pulsaçōes ror minu to. Os gânglios linfáticos superficiais apresentavam nítido aumen to de volume.

o exame da pele permitiu verificar formaçõcs noduiar»s, ora de consistencia firme, ora flutuantes, ora ulcerados e trajeto fis tulosos pelos quals fluia secreção de aspecto purulento. Material. dêsses nódulos fol recolhido para cxame microbiológlco e una 
imostrá de sangue fol colctada para informações hematológlcas. Em relação a estas últimas, encontramoa leucocitose moderada, com neu trafilla e desvio à esquerda, além de monocltose, com os scguintes dados:

Leucócitos _ $\quad 27.500$

Neutrófilos $\left\{\begin{array}{lll}\text { segmentados } & - & 58,25 \% \\ \text { bastonetes } & - & 14,75 \% \\ \text { jovens } & - & 2,75 \%\end{array}\right.$

\begin{tabular}{lll} 
Eosinófilos & - & $0,25 \%$ \\
Linfócitos & - & $7,5 \%$ \\
Monócitos & - & $16,5 \%$ \\
\hline
\end{tabular}

C exame unicroblológlco revelou desde logo, em esfregaço: do pus, corados pelo Gram, número considerável de "formas en charu to", caracterfsticas do Sporophricum shencki e as culturas em ágar-íabouraud raltosado e gli icosado confimaram o achado.

Estabelecido o diagnóstico de esporotricose, foi instituí do tratamento com griseofulvina (Grifulvin), durante ? mês, sem resultados aparentes. Ao contrário, a administração de lodeto de potássio (l grana diária, via oral), nrescrita em substitui ção, conduziu à ráplda melhora chegando mesmo a dar impressão de cu ra, decorridos cêrca de 20 dias de tratamento.

Todavia, meses após fomos notificados que o animal havia sldo sacriflcado em virtude de recldiva do processo, não nos tendo sido apresentada a oportunidade de necropsiá-10.

o modo pelo qual teve inf́lo êste caso, colncidindo o ape recimento da micose no local mais atacado por môscas hematófagas e - fato informado mals de uma vez pelo proprietário, de que o cão 
não tirha contacto com vegetais - "habltat" natural do Sporothricum shencki - levou-nos a admitir a hipótese de que o cogumelo po deria ter sido depositado nas feridas jor anuêles insetos, trazido talvez de uma fonte de infeç̧ão representada por eqlinos ou muares, alojados nas vizinhorças.

Caso 2. Em 77.10 .62 examinamos um cão sem raça deflnida, macho, de talhe médio, com 6 arus de idade.

A histórta clfinca envolvia una afeção cutânca de cará ter emptivo, com prurido discreto, que havia sido tratada com cor ticosteroides, quinioterápicos e antibióticos, scm resultado.

0 animal, tinha constituição forte e appesentava bom estą do de nutrição. o exame geral não apontou alterações dá normal:da de em relação à temperutura, ao pulso c à respiração.

hs lesões da pele, de caráter úlcero-gomoso, traduzlam-se por formações nodulares de consistência variável e lrajetos fistulo sos dos quais vazava sccreção purulento-hemorráglca. Algumas árcas lesadas achavam-se recobertas por crostas escuras que, removidas, expunham uma superff́cie ulcerada que sangrava facilmente.

os gânglios linfáticos poplíteos e pré-axilares exiblam e. vidente aumento de volume.

A suspelta clfnica de esporotricose fol confirmada pelo cxame microblológlco do raspado das lesões. As clássicas "forma: em chamuto" foram faclimente evidencludas e culturas tfpicas foram conseguidas em meio de Sabouraud maltosado e glicosado, mantidas cm ambiente e a $37^{\circ} \mathrm{C}$.

Fol inst1tuido tratamento com lodeto de potássio, mas não tivemos mais notícta do caso, pols o proprictário não voltou ao 
Nos casos aqui relatados, a esporotricose tere a configu rá-1a o tipo úlcero-gomoso das lesöes, representado por formações nodulares em diferentes graus de evolução: algumas, de consistên cla flrme; outras de consistêncla gomosa e outras alnda, ulceradas e às vêzes recobertas por crostas fàcilmente destacávels. Trajetos Ilstulosos completavarn o quadro e dêles escoava secreção purulento hemorráglca.

Havia reação Ilnfática reglonal beso evidente. 0 quadro henático, em um dos casos, revelou-se alterado, mas não de forma es pecffica e sim tal qual se apresenta nos processos infecciosos em geral, com leucocitose e desvlo à esquerda.

$\mathrm{Na}$ secreção e cm raspados das úlceras, pudemos evidenciar as clásslcas "formas em charuto" que caracterizam o parasita. E. te material proporcionou a obtenção de boas culturas nos melos de Sabouraud glicosado e maltosado, quer quando desenvolvidas cm tempe. ratura amblentc, quer a $37^{\circ} \mathrm{C}$.

En amblente, 4 a 5 dias após a semeadura já se eviden claran colôntas, de inflcio semelhantcs a colôntas bacterianas, que gradativamente assumiram o aspecto fúrglco, de superficle aveludada, centro enumgado, bordos irregulares e plgmentação pardo-negra pro zressiva. O exame do micélio revelou hifas septadas e ramiflcadas, com conidiósporos a longo do trajeto ou aglomerados concêntricamen te nas extremidades. As culturas incubadas a $37^{\circ} \mathrm{C}$, deram origem a 
colônias cromosas cercoriturties, com micéilo leveduriforne. Tals dados corduziram-nos a fdertiffoar o parastla como Sporothricum shencki .

R E S U M O

Os autores apresentam dols casos de esporotricose em cães, múcose ainda não assinalada nessa espécio, en S. Paulo.

O processo, em ambos os casosi, teve evclução crônica, não afetou aparentemente o estado geral dos aninals e caracterizou-se por lesões cutâneas de caráter úlcoro-gomoso em diferentes graus de deservolvımento, corfflghradas por formações nodulares de coriststência diversa, áreas ulceradas e trajetos fistulosos dos quals vazava se

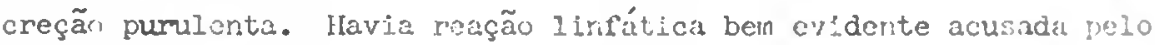
pronunciado aunento de volume dos tânglios regionals.

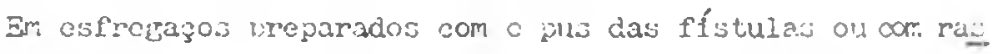
pados das líccras, corados pelo Gram, o parajita foi facimente re corhecido pela sua "forma em chamito". Foram obtida: culturas té picas em Saburald maltosado e gilcosado, em temperntura amibente e a $37^{\circ} \mathrm{s}$.

im un dos casos, o tratamento com Erfecofurvina "(Griful vin)" não teve êxito. A administração de lodeto de cotásslo rever teu em rárida melhor:l, aparentando cura, forém houve recldiva aró: alguns̃ meses. 


\section{S U M M A R Y}

For the flrst time in Brazil Sporothricosis is described in dogs.

In the two cases studied the disease was characterized by the appearance of cutaneous nodes of different consistences and sometimes ulcerous, covered with dark scabs.

Fistulous openings complete the lesion and pumulent dis. charge could be observed as well as involvement of the drainage $11 \mathrm{mph}$ nodes.

In the contents of the nodes, in the purulent exudates of the fistulae and the scrapings of the ulcers, there were many para sites, in characteristics "cigar shape".

Cultures were obtained easily at room temperature and at $37^{\circ} \mathrm{C}$

The disease followed a chronic course and no marked con st1tucional symptoms were noted.

In one of the cases the treatment with Griseofulvina was not successfull but the ministration of potassium lodine resulted in a quick but false recovery, because after some months there was a recrudescency. 


\section{RFFERENACIAS BIBLIOGRÁFILAS}

Ao tempo em que observávinos r.ossso casos raccbcmos comuncayão pes. soai do Er. Rrymonio Mertins de vastro (F.M. L'3I') sobre un caso de espotricose em cão, por êle 1dentificario.

FREITAS, D.C. de - MIGIIANO, M.F. - ZANI NEDO, L. - 1956 - Fsporotr王

cose : Observação de cáso espontârieo em gato doréstico. (F. catus, I.) Rev. Fac. Med. Vet. S. Paulo, 2 (4):601-1j04

LACAZ, C.S. - 1960 - Manual de Micologia Méd1ca. 3a. ed. Rio de Jane1ru, Livraris. Atheneu S/A. p. 370

LEĂO, A.E. de Area - SILVA, J.0. - PROENZA, M. - 1935 - "Sur un cas de Sporothricose a "Sporothricum Beurmanni" (observé nour la primière fols chez un mulet)". Bcl. Vet. Exército, Rio de Jane1ro, $\quad 2(3): 45-49$

LUTz, A. - SILENDORie, A. - 1907 - Sôbre uma micose observada em ho mens e ratos (Contribulção para o conhecimento das assim chama das 3porothricoses). Rev. med. S. Paulo, 10 (21):433-450

MELIO, A. - 1935 - Un caso de esporotr1cose verrugo1de por "sporo thricum Beurmanni ". Rev. Ind. anim., 르 (3):305-314

PIPRININGA, S. N. - 1943 - Esporotricose em imuar. Rev. Fac. Med. Vet. S. Paulo, $\underline{2}(3): 219-222$

SOUZA, J.J. de - 1957 - F.sporotricose em cães. An. VII Congr.

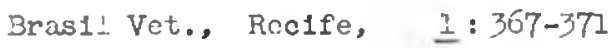


VANBRLUSEGHEM, R. - 1958 - Mycoses of mar and an1mals. London, S1r Isaac P1tmann \& Sors, Ltd. p. 224 



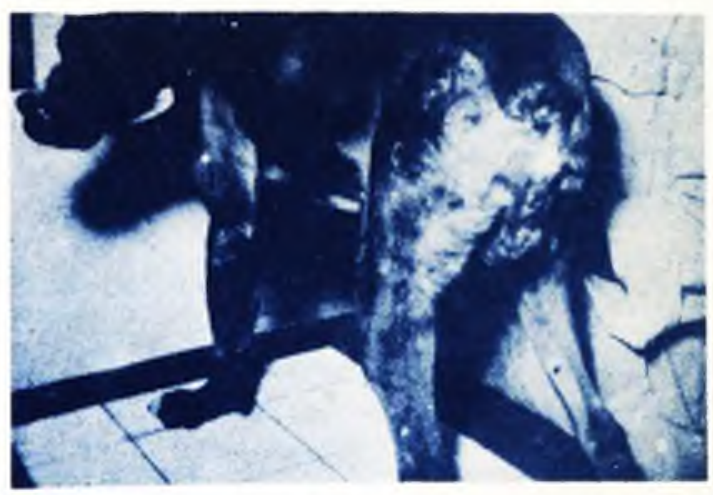

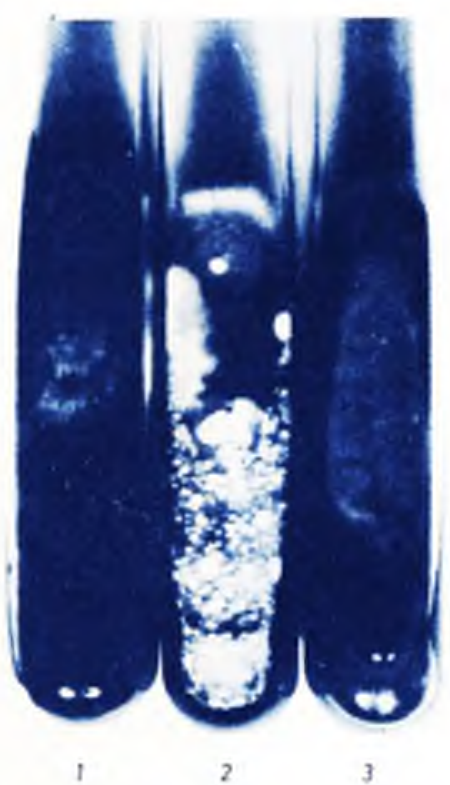

FIGURA II

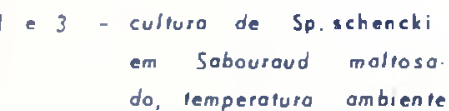

2 - idem incubada a $37^{\circ} \mathrm{C}$ e

depors mantida em ambiente

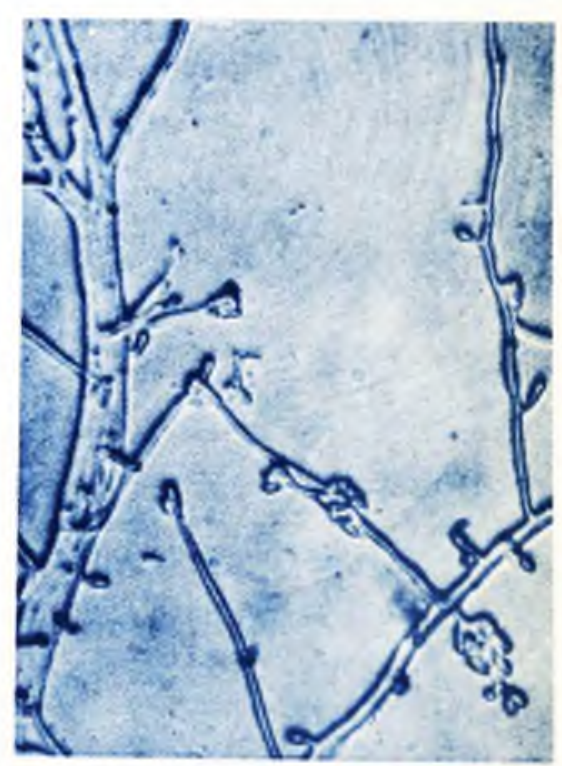

FIGURA III

Culfura em Idmina hifas e canidiósporos. 